\title{
Aids e seguridade social brasileira: análise dos benefícios concedidos na previdência e assistência social, 2004-2016
}

\author{
Aids and Brazilian social welfare: analysis of benefits granted \\ in social security and social assistance, 2004-2016
}

Keile Aparecida Resende Santos (https://orcid.org/0000-0002-9171-461X) 1,2 Antônio Marcos Machado de Oliveira (https://orcid.org/0000-0002-8459-6782) ${ }^{2}$ Antônio Miguel Gonçalves Bós (https://orcid.org/0000-0002-6889-1781) ${ }^{3}$

Luciomar de Melo (https://orcid.org/0000-0002-6233-049X) ${ }^{1}$

Jean Ezequiel Limongi (https://orcid.org/0000-0003-2649-9842) ${ }^{2}$
${ }^{1}$ Instituto Nacional do Seguro Social. Praça

Clarimundo Carneiro 162, Centro. 38400-198 Uberlândia MG Brasil. keileaparecida62@ gmail.com

${ }^{2}$ Universidade Federal de Uberlândia. Uberlândia MG Brasil.

${ }^{3}$ Tusculum College.

Tennessee Estados Unidos da América.

\begin{abstract}
The study explores the distribution of AIDS through sociodemographic variables, within the scope of Brazilian social security and social assistance. Twenty-seven federal units were used for data spatialization and analysis. Data were stratified according to gender, age group, area of residence, social welfare membership, type of benefit received and grant method for the beneficiaries. Benefits were classified as social security $(71,939$, $72.4 \%)$, social assistance $(26,302,26.5 \%)$ and accident benefits $(1,128,1.1 \%)$, a large proportion of which were granted to males $(64,654,65.1 \%)$. The unemployed (50,404, 50.7\%), who lived in urban areas $(96,767,97.4 \%)$, were aged between 20 and 39 years $(49,508,49.8 \%)$ and who received benefits based on article 27 of Decree $N^{\circ}$ 3048/99 (51,985, 52.3\%) were the most incident. The results show that more than half of the benefits granted were for unemployed individuals or those without job stability and, thus, did not contribute to social security for continuous periods. This fact reaffirms the segregation in the labor market to which these individuals are subjected. Also, it is noted that AIDS persists at high levels at the most productive stage of life.
\end{abstract}

Key words AIDS, Social Security, Social Assistance
Resumo O estudo explora a distribuição da aids, por meio de variáveis sócio demográficas, no âmbito da previdência e assistência social brasileira. Para a espacialização e análise dos dados foram utilizadas as 27 unidades federativas. Os dados foram estratificados de acordo com o sexo, faixa etária, zona de residência, forma de filiação na seguridade social, tipo de benefício recebido e a forma de concessão para os beneficiários. Os benefícios foram distribuidos em previdenciários (71.939; $72,4 \%)$, assistenciais (26.302; 26,5\%) e acidentários $(1.128 ; 1,1 \%)$, sendo grande parte concedida $a$ indivíduos do sexo masculino (64.654; 65,1\%). Os desempregados (50.404; 50,7\%), residentes em área urbana (96.767; 97,4\%), faixa etária entre 20-39 anos (49.508; 49,8\%) e que tiveram a concessão do benefício baseado no artigo 27 do Decreto 3048/99 (51.985; 52,3\%) foram os mais incidentes. Os resultados revelam que mais da metade dos benefícios concedidos foram para indivíduos desempregados ou que não possui estabilidade nos empregos e, por conseguinte não se mantém contribuindo com a previdência social por períodos contínuos. Esse fato reafirma a segregação no mercado de trabalho a que estes indivíduos estão submetidos. Além disso, destaca-se que a doença persiste em níveis elevados na fase da vida mais produtiva.

Palavras-chave Aids, Previdência Social, Assistência Social 


\section{Introdução}

Ao final da década de 1980 no Brasil, a aids era motivo de grande preocupação social, com repercussões importantes na saúde pública e na esfera econômica. A síndrome se mantinha com alta incidência entre os grupos mais vulneráveis e se propagava entre mulheres e homens heterossexuais $^{1}$. De 1980 a junho de 2017, foram confirmados no Brasil 882.810 casos de aids, com média anual de 40 mil casos novos nos últimos cinco anos, sendo mais incidente entre os homens $(576.245 ; 65,3 \%)$ do que entre mulheres (306.444;34,7\%). As taxas de detecção de aids em homens nos últimos dez anos têm apresentado tendência de crescimento; em 2006, a taxa foi de 24,1 casos/100.000 hab., a qual passou para 25,8 em 2016, representando um aumento de 7,1\%. Entre as mulheres, nota-se tendência de queda dessa taxa nos últimos dez anos, que passou de 15,9 casos/100.000 hab., em 2006, para 11,6 em 2016, representando uma redução de $27,0 \%$. A razão de sexos apresenta diferenças regionais importantes. Nas regiões Sudeste e Centro-Oeste, há um predomínio de homens em comparação com as demais regiões, sendo a razão de sexos, em 2016, respectivamente, de 25 e 26 casos em homens para cada 10 casos em mulheres. Por sua vez, nas regiões Norte e Nordeste, a razão de sexos, em 2016, foi, respectivamente, de 22 e 21 casos em homens para cada 10 casos em mulheres, enquanto na região Sul há uma participação maior das mulheres nos casos de aids, sendo a razão de sexos de 17 homens para cada 10 mulheres. A maior concentração dos casos de aids no Brasil está nos indivíduos com idade entre 25 e 39 anos, em ambos os sexos. Os casos nessa faixa etária correspondem a 52,9\% dos casos do sexo masculino e, entre as mulheres, a $49,0 \%$ do total de casos registrados ${ }^{2}$.

A distribuição proporcional dos casos de aids, identificados de 1980 até junho de 2017, mostra uma concentração nas regiões Sudeste e Sul, correspondendo cada qual a $52,3 \%$ e $20,1 \%$ do total de casos. As regiões Nordeste, Centro-Oeste e Norte correspondem a 15,4\%, 6,1\% e 6,0\%, respectivamente ${ }^{2}$. Além disso, observou-se que, entre as unidades federativas (UF), 16 apresentaram taxa inferior à nacional (de 18,5/100.000 habitantes), sendo o Acre o estado com a menor taxa $-8,7$ casos $/ 100.000$ hab.

Os impactos sociais da aids, seja por conta do aumento do número de infectados pelo HIV, seja pelo estigma da doença, possuem importantes reflexos na economia. A grande maioria dos ca- sos encontra-se na população economicamente ativa. Além disso, os custos do tratamento são bastante elevados. O orçamento atual do Ministério da Saúde (MS) para a aquisição de antirretrovirais é de $\mathrm{R} \$ 1,1$ bilhão ${ }^{3}$. No caso específico do Brasil, acrescenta-se a esse cenário o fato de que além dos gastos com o tratamento das pessoas vivendo com HIV/aids, existem os gastos com a previdência e a assistência social dos indivíduos acometidos pela doença. Trata-se, portanto, de um impacto significativo nos três pilares da seguridade social.

Desde 2013, como recomendado pela Organização Mundial da Saúde (OMS), todos os indivíduos com HIV no Brasil, independente da contagem de células CD4, recebem terapia antirretroviral. Esta estratégia aumenta a expectativa de vida e diminui o risco de transmissão viral ${ }^{4}$. Além disso, em 2017, o Brasil foi um dos primeiros países no mundo a oferecer gratuitamente o antirretroviral Dolutegravir, medicamento mais recomendado pela OMS para o tratamento HIV/ aids ${ }^{5}$. Com o diagnóstico oportuno, acesso aos medicamentos atuais e boa aderência ao tratamento ao longo da vida, pessoas com infecções adquiridas recentemente podem ter uma expectativa de vida quase igual à de um indivíduo HIV negativo, ultrapassando 50 anos em algumas estimativas ${ }^{6,7}$. Diante dos avanços alcançados na terapêutica da aids nos últimos anos, espera-se que haja uma diminuição do número de indivíduos doentes que realmente necessitem de afastamento laboral, sob o risco de haver grande oneração para o país em duas direções: no tratamento de doentes e na concessão de benefícios em longo prazo $^{8}$.

Esse estudo analisou informações consolidadas nacionalmente relativas à concessão de benefícios previdenciários, acidentários e assistenciais às pessoas vivendo com aids, segurados ou não, pelo Regime Geral de Previdência Social do Brasil (RGPS). O uso do geoprocessamento permitiu a análise espacial de variáveis do banco de dados da RGPS brasileira, permitindo o reconhecimento do impacto da doença na seguridade social brasileira e a compreensão de contextos específicos destacados por UF.

\section{Metódos}

Foi realizado um estudo exploratório, do tipo ecológico, com base em dados secundários, obtidos do Sistema Único de Informações de Benefícios do Ministério da Previdência e Assis- 
tência Social do Brasil (SUIBE). Este sistema de informação não é de livre acesso e possui dados sócio demográficos e epidemiológicos dos beneficiários. No SUIBE foram selecionados todos os beneficiários com o registro B24 (Doença pelo vírus da imunodeficiência humana [HIV] não especificada) na variável Código Internacional de Doenças (CID) entre o período de 2004 e 2016. Este sistema foi implantado em meados de 2003, porém somente em 2004 tornou-se mais robusto, por isso a escolha deste ano para o início da coleta de dados. As variáveis de interesse para o estudo foram exportadas para uma planilha Excel. O programa Epi Info 7.1.5 (CDC, Atlanta, USA) foi utilizado para a análise de consistência, distribuição de frequências e estratificação dos dados.

Foram analisadas as variáveis: sexo, faixa etária (0-9, 10-19, 20-39, 40-59 e 60 anos ou mais)., zona de residência (urbana e rural), unidade federativa, forma de filiação na seguridade social (desempregado, empregado, contribuinte individual e outros), tipo de benefício recebido (previdenciário, acidentário, assistencial e os subgrupos de cada tipo) e a forma de concessão do benefício (concessão normal, concessão com base no artigo 27 do Decreto 3048/99 e outros).

Para cada unidade federativa foram calculadas no período a taxa de detecção de aids, a razão número de casos de aids/Número de benefícios concedidos e a taxa de incidência de benefícios. A população brasileira de 2010 foi utilizada para os cálculos dos indicadores populacionais, por serem os dados do último censo brasileiro, além de constituir o ano mediano na serie histórica estudada. Para avaliar a correlação entre o número de casos de aids e o número de benefícios por unidade federativa foi utilizada a correlação de Spearman.

Para a espacialização dos dados foi utilizado o Sistema de Informação Geográfica - SIG, QGIS 2.18 , com o qual foi possível elaborar os mosaicos de mapas. As unidades analíticas foram as 27 UF, sendo 26 estados e um distrito federal, como definido pelo Instituto Brasileiro de Geografia e Estatística (IBGE).

Foram calculados os gastos da previdência e assistência social com novas concessões relacionadas à aids no ano de 2016 e comparados com os gastos totais da previdência e assistência social do mesmo ano.

Este estudo foi aprovado pelo Comitê de Ética em Pesquisa da Universidade Federal de Uberlândia, Minas Gerais, Brasil.

\section{Resultados}

No período analisado foram registrados 517.326 casos de aids no Brasil e 99.369 benefícios de seguridade social foram concedidos a pessoas vivendo com aids, sendo eles, benefícios previdenciários (71.939; 72,4\%), assistenciais (26.302; $26,5 \%)$ e acidentários (1.128; 1,1\%). Grande parte dos benefícios foi concedida a indivíduos do sexo masculino $(64.654 ; 65,1 \%)$. Entre os sexos, cada tipo de benefício seguiu a mesma tendência de distribuição percentual, porém, entre indivíduos do sexo feminino, os benefícios assistenciais tiveram uma frequência maior quando comparados aos do sexo masculino, $36,1 \%$ e $21,3 \%$, respectivamente.

Os benefícios foram mais incidentes nas faixas etárias 20-39 anos $(49.508 ; 49,8 \%)$ e 40 59 anos $(45.080 ; 45,4 \%)$. Entre os beneficiários de 20 a 39 anos, as espécies de benefícios mais incidentes foram Auxílio-doença previdenciário (34.017; 68,7\%) e Amparo assistencial ao portador de deficiência (12.330;24,9\%), assim como na faixa etária de 40 a 59 anos, Auxílio-doença previdenciário (28.382; 62,9\%) e Amparo assistencial ao portador de deficiência $(11.144 ; 24,7 \%)$. Nesta faixa também foi importante o número de benefícios Aposentadoria por invalidez previdenciária (5.059; 11,2\%).

As maiores taxas de detecção de aids no período estudado foram nas UFs do Rio Grande do Sul, Santa Catarina e o Rio de Janeiro, respectivamente. As maiores taxas de incidências de benefícios assistenciais foram nas UFs Amapá, Rondônia e Amazonas, respectivamente (Tabela 1). Em relação às taxas de incidências de benefícios previdenciários e acidentários houve maiores taxas de incidências nas UFs Santa Catarina, Rio Grande do Sul e Rio de Janeiro. As UFs do Rio Grande do Norte, Acre e Roraima apresentaram as maiores razões de número de casos de aids/No de benefícios concedidos, enquanto Rondônia, Amapá e Paraíba as menores razões (Tabela 1).

Houve correlação fortemente positiva quando se analisou a distribuição demográfica do número de casos de aids em relação a distribuição demográfica de beneficiários por causa da aids ( $\mathrm{r}$ $=0,97 ; \mathrm{p}<0,0001)$.

A Figura 1 analisa espacialmente os tipos de concessões de benefícios concedidos pelas Agências de Previdência Social do Brasil (APS) por UF. As concessões com base no artigo 27 do Decreto 3048/99 foram as mais incidentes (51.985; $53,3 \%)$, seguido das concessões normais 46.103; $(46,4 \%)$ e "Outros" tipos de concessões (1.281; 


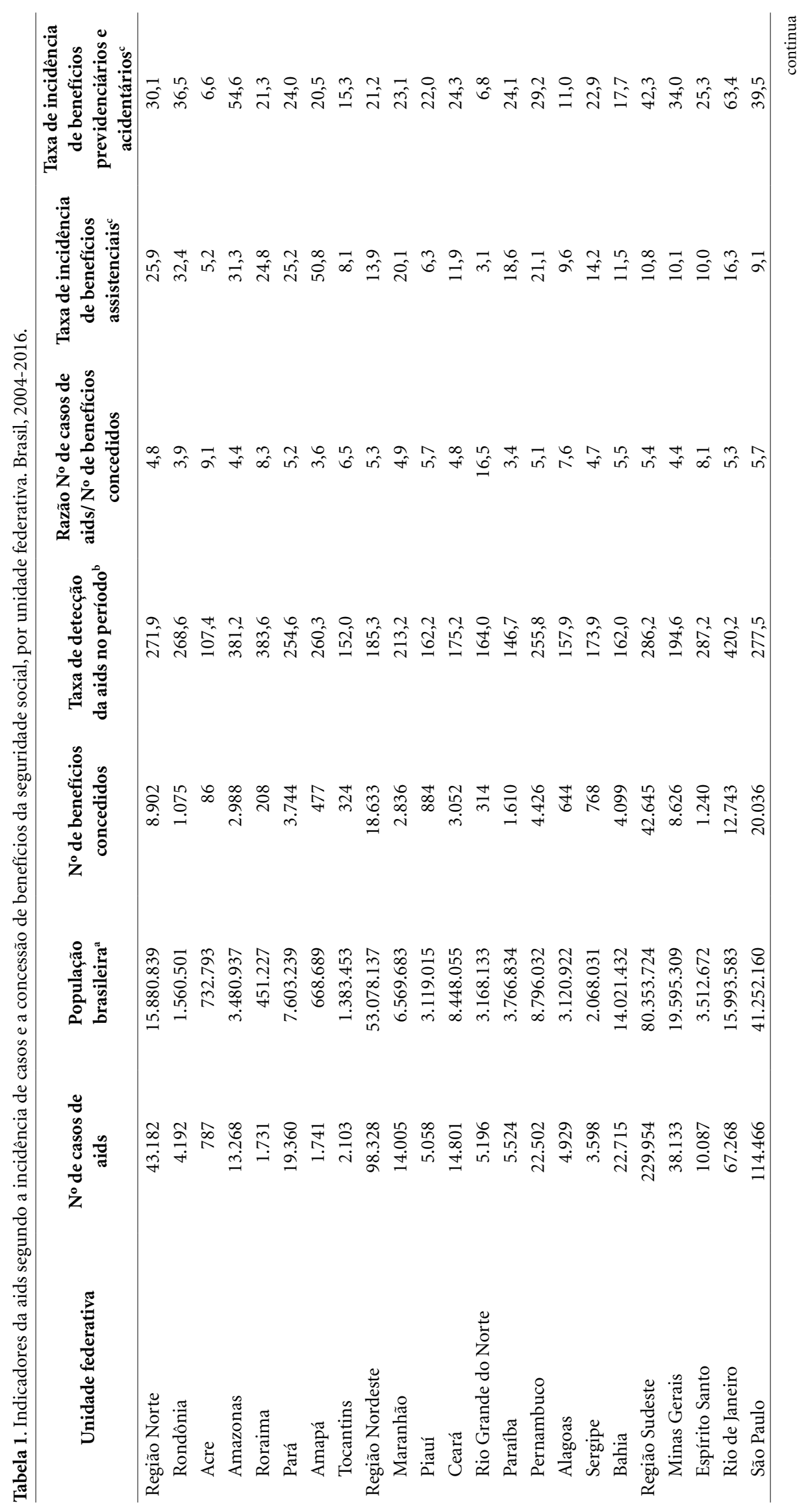




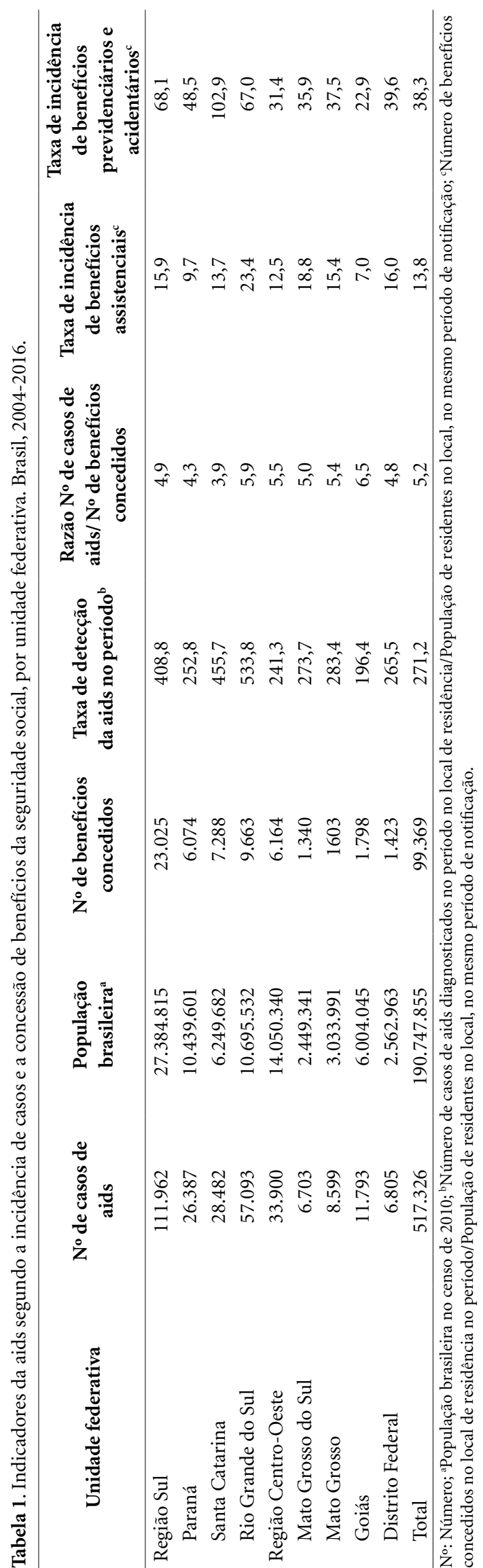

$1,3 \%)$. As concessões com base no artigo 27 do Decreto 3048/99 foram mais incidentes nas UFs do Rio de Janeiro (619,4 por 1000 benefícios) e Goiás (594 por 1000 benefícios). Amapá e Acre tiveram as maiores taxas de incidências de concessões normais, com 771,5 e 697,7 concessões por 1.000 benefícios, respectivamente. Outros tipos de concessões foram mais incidentes no Acre (23,3 por 1000 benefícios) e Amapá (23,1 por 1000 benefícios).

A Figura 2 analisa os benefícios de acordo com o tipo de filiação dos beneficiários na previdência social brasileira. No total, 50.404 (50,7\%) benefícios foram concedidos para beneficiários desempregados, grande parte deles recebendo o benefício assistencial Amparo assistencial ao portador de deficiência (24.710; 49,0\%) e Auxílio-doença previdenciário $(22.239 ; 44,1 \%)$. As maiores taxas de incidência de benefícios a desempregados foram nas UFs do Amapá (819,7 por 1000 benefícios) e Roraima (716,1 por 1000 benefícios). As 14 maiores taxas de incidência de benefícios a desempregados foram em UFs do norte e nordeste do Brasil. Foram concedidos 28.775 $(28,9 \%)$ benefícios a beneficiários empregados, sendo 25.416 (88,3\%) da espécie Auxílio-doença previdenciário e 2786 (9,7\%) da espécie Aposentadoria por invalidez previdenciária. As maiores taxas de incidência de benefícios a empregados foram nas UFs Goiás (345,9 por 1000 benefícios) e Santa Catarina (342,5 por 1000 benefícios). Entre os contribuintes individuais, foram concedidos 12.625 (12,7\%) benefícios, sendo 10.131 (80,3\%) da espécie Auxílio-doença previdenciário e $1620(12,8 \%)$ da espécie Aposentadoria por invalidez previdenciária. As maiores taxas de incidência de benefícios para contribuintes individuais foram nas UFs do Rio de Janeiro (183,2 por 1000 benefícios) e Santa Catarina (181,4 por 1000 benefícios). Dentre a categoria "Outros", filiados ao RGPS, foram agrupados os empregados domésticos (2.997; 3,2\%), segurados especiais ( $2.498 ; 2,5 \%)$, os facultativos $(1.751 ; 1,8 \%)$, além de outras formas de filiação com percentagens menores. Foram concedidos 7.565 (7,6\%) benefícios nesta categoria, sendo a maioria (5.986; 79,1\%) da espécie Auxílio-doença previdenciário e 762 (10,1\%) da espécie Aposentadoria por invalidez previdenciária. As maiores taxas de incidência de benefícios para a categoria "Outros" foram nas UFs do Maranhão (219,7 por 1000 benefícios) e Piauí (181,0 por 1000 benefícios).

A Figura 3 avalia a concessão dos benefícios por zona de residência. A maioria dos benefícios (96.767; 97,4\%) foram concedidos para bene- 

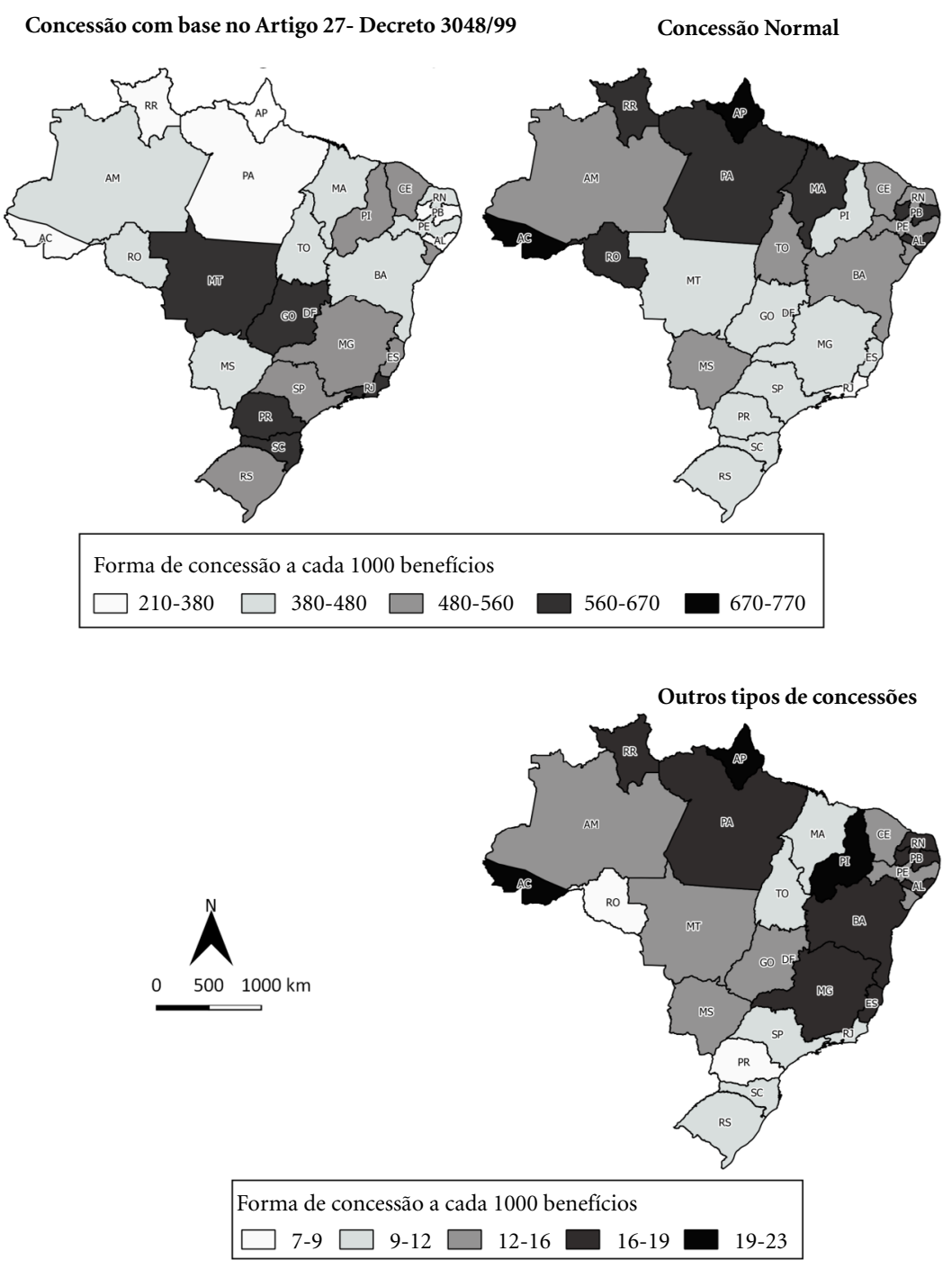

Figura 1. Forma de concessão de benefícios da seguridade social relacionados à aids. Brasil, 2004-2016.

Fonte: Ministério da Previdência Social, 2016.

ficiários residentes em zona urbana, principalmente das espécies Auxílio-doença previdenciário (61.557; 63,6\%) e Amparo assistencial ao portador de deficiência 26.226 (27,1\%). Para beneficiários residentes na zona rural foram mais comuns os benefícios da espécie Auxílio-doença previdenciário $(2.215 ; 85,1 \%)$ e Aposentadoria por invalidez previdenciária $229(8,8 \%)$. As maiores taxas de incidência de benefícios para residentes da zona urbana foram nas UFs Rio de Janeiro (998,9 por 1000 benefícios) e São Paulo (997,8 por 1000 benefícios). As UFs Maranhão (192,9 por 1000 benefícios) e Piauí (145,9 por 1000 benefícios) foram as que apresentaram maiores taxas de incidência de benefícios na zona rural.

Para o ano de 2016, analisamos o impacto econômico das novas concessões de benefícios previdenciários, acidentários e assistenciais concedidos a beneficiários que convivem com a aids em relação ao total geral de novas concessões de benefícios no Brasil no mesmo ano. Foram concedidos 5.132.278 benefícios no Brasil neste ano. 

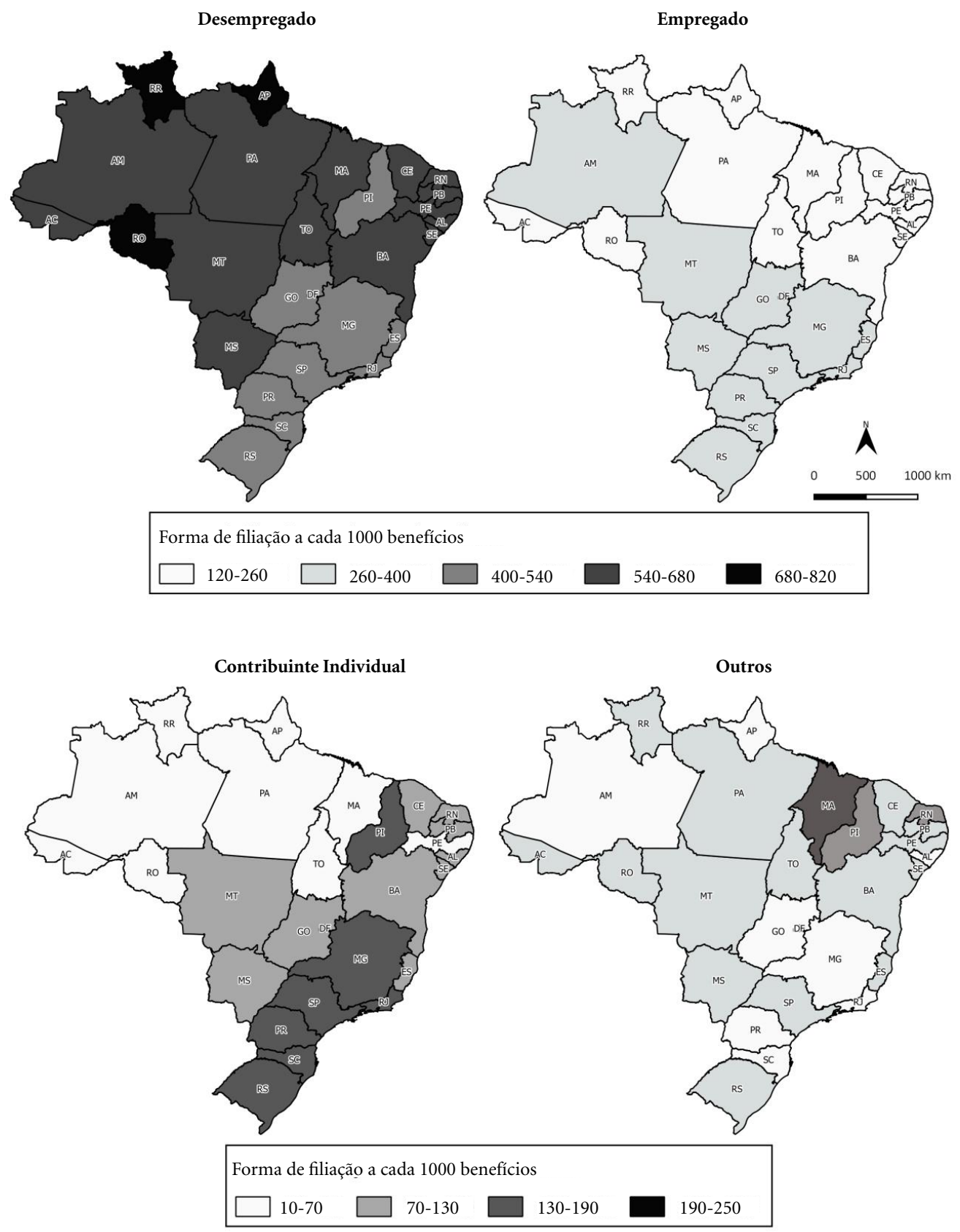

Figura 2. Forma de filiação dos beneficiários da seguridade social que vivem com aids. Brasil, 2004-2016.

Fonte: Ministério da Previdência Social, 2016.

Deste total, $8.677(0.17 \%)$ foram benefícios para indivíduos que convivem com a aids. Entre indivíduos do sexo masculino, o percentual de aids foi maior, 5.743 benefícios em 2.228 .069 benefícios da previdência e assistência social, o que equivale a $0.26 \%$. Por outro lado, benefícios para o sexo feminino a indivíduos que convivem com a aids foram $2.934 \mathrm{em} \mathrm{2.904.382,} \mathrm{o} \mathrm{que} \mathrm{equivale}$ a $0,10 \%$.

O gasto total no ano de 2016 com novas concessões de benefícios relacionados à aids foi de $\mathrm{R} \$ 72.243 .544,00$. O gasto mensal médio com 


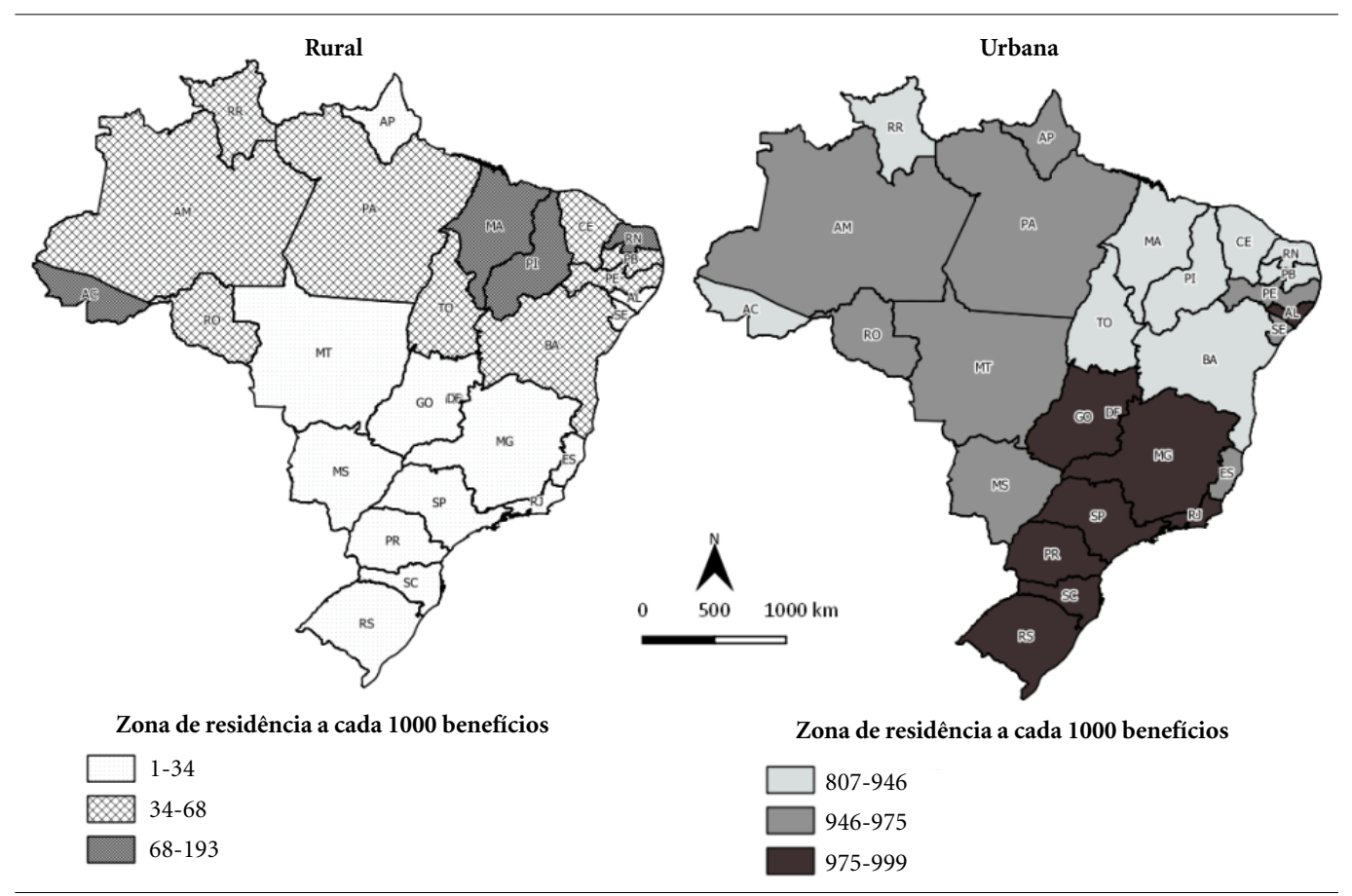

Figura 3. Zona de residência dos beneficiários da seguridade social que vivem com aids. Brasil, 2004-2016.

Fonte: Ministério da Previdência Social, 2016.

novos benefícios em 2016, relacionado à aids, foi de $\mathrm{R} \$ 1.095,42$, menor que o gasto mensal médio geral da previdência e assistência social, que foi de $\mathrm{R} \$ 1.305,40$. Entre os indivíduos do sexo masculino, o gasto mensal médio foi maior, quando comparado com os gastos entre o sexo feminino, $\mathrm{R} \$ 1,169,68$ e $\mathrm{R} \$ 950,07$, respectivamente.

Ao final do período analisado, entre os 95.162 benefícios em que havia dados de acompanhamento, 30.399 (31,9\%) ainda estavam ativos, $64.366(67,6 \%)$ cessados e $397(0.42 \%)$ bloqueados.

\section{Discussão}

Atualmente, a discussão sobre a situação da seguridade social brasileira, em especial a previdência social, gera controvérsias em relação à sua sustentabilidade ${ }^{9}$. No que concerne a aids, uma síndrome crônica altamente estigmatizante, esta discussão torna-se ainda mais importante. O sistema de informação de dados previdenciários e assistenciais no Brasil (SUIBE) não é de livre acesso, e em decorrência disso, pouquíssimos estudos tratam dessa temática no país. Este estudo, de caráter inédito no Brasil, procura analisar a aids no âmbito da previdência e assistência social, utilizando-se de dados individuais de todos os beneficiários no Brasil durante 12 anos.

O estudo revelou que a maioria dos benefícios concedidos pelas APS foram os previdenciários, predominantemente para o sexo masculino. Isso pode ser explicado, em partes, pelo fato de que o número de casos de aids em homens nos últimos 10 anos tem apresentado tendência de aumento $^{2}$. A prevalência de HIV entre homens que fazem sexo com outros homens aumentou de $12,1 \%$ em 2009 para $18,1 \%$ em 2016, conforme estudo realizado em 12 cidades brasileiras. Por outro lado, há uma nítida desigualdade na oferta de trabalho, sendo mais evidente a informalidade concentrada no sexo feminino ${ }^{10}$. A segregação setorial, profissional e até mesmo com índices menores de remuneração contribuem significativamente para as disparidades de sexo, quer em termos do número, quer na qualidade dos postos de trabalho. Essas desigualdades repercutem no acesso limitado à proteção social relacionada com o labor, onde esses regimes existem, o que denota importante elemento da vulnerabilidade feminina ${ }^{11}$. O trabalho informal e com menores 
remunerações para as mulheres impactarão futuramente na cobertura dos regimes contributivos, tais como o RGPS.

As maiores taxas de detecção de aids no período analisado foram nas UFs do Rio Grande do Sul, Santa Catarina e Rio de Janeiro. De acordo com o Boletim Epidemiológico HIV AIDS 2017, em uma comparação da taxa entre os anos de 2006 e 2016, no entanto, houve declínio de 17,6\%, $22,3 \%$ e $21,4 \%$ nestas UFs, respectivamente. Porém, em 2016, o Rio Grande do Sul apresentou a segunda maior taxa de detecção no país, com 31,8 casos/100.000 hab. ${ }^{2}$.

As taxas de incidências de benefícios assistenciais foram maiores no Amapá, Rondônia e Amazonas. Estes dados refletem as características sócio econômicas da região norte do país. Por outro lado, as taxas de incidências de benefícios previdenciários/acidentários foram maiores em Santa Catarina, Rio Grande do Sul e Rio de Janeiro. Essas regiões são mais desenvolvidas, com grandes polos industriais e a chance de empregos formais torna-se maior ${ }^{12}$.

As UFs do Rio Grande do Norte, Santa Catarina e São Paulo apresentaram as maiores razões de Número de Casos de aids/Número de benefícios assistenciais. Para o Rio Grande do Norte, por exemplo, para cada 52,5 casos de aids, 1 benefício assistencial era concedido. Para a razão Número de Casos de aids/Número de benefícios previdenciários e acidentários as UFs com maiores razões foram o Rio Grande do Norte, Roraima e Acre. Novamente tomando o exemplo do Rio Grande do Norte, para cada 24,2 casos de aids, 1 benefício previdenciários ou acidentários era concedido. Este dado pode ser interpretado de três maneiras: os casos notificados podem estar em plena atividade laboral, sem a necessidade de gozo de benefícios da previdência ou assistência social. Estes casos também podem não estar enquadrados nos critérios para a concessão de benefícios, previdenciários ou assistenciais. Outra possibilidade seria que estes casos não teriam acesso aos direitos sociais que lhe são segurados.

Outra questão essencial neste estudo trata-se das elevadas taxas na concessão de benefícios com relação a faixa etária dos 20-59 anos, as quais coincidem com o período da vida mais produtivo. Sendo assim, uma incapacidade laboral neste período reflete diretamente no mercado de trabalho e no sistema financeiro e atuarial. A redação do art. 201 da CF, expressa tacitamente que "a previdência social será organizada sob a forma de regime geral, de caráter contributivo e de filiação obrigatória, observados critérios que preservem o equilíbrio financeiro e atuarial"13. Os princípios do equilíbrio financeiro e atuarial pretendem direcionar o Sistema Previdenciário em sua gestão, para que sempre seja viável a sua manutenção. A Previdência Social possui suas fontes de arrecadação, entre elas, as contribuições previdenciárias pagas pelos empregados e empregadores e possui, também, as suas despesas, como as prestações que deve pagar aos segurados, aposentadorias e auxílios-doença. O equilíbrio financeiro que almeja a CF é que, ao final do período, depois de feita toda a arrecadação e efetuadas todas as despesas, não exista um saldo negativo na previdência, o que pode, se ocorrer repetidamente, levar a inviabilização de todo o sistema. Por outro lado, o equilíbrio atuarial é a maneira que se buscará o equilíbrio financeiro, isto porque a atuária, uma ciência exata, que por meio de diversos fatores é capaz de prever os gastos futuros da previdência e, com base nestes, possibilitar a melhor gestão da arrecadação e pagamentos, não perdendo de vista as obrigações que irão existir em um futuro não muito distante.

Os resultados revelam que mais da metade dos benefícios concedidos foram para indivíduos desempregados. Um dos requisitos básicos para a concessão dos benefícios previdenciários relaciona-se a estar segurado pelo RGPS, ou seja, ter a qualidade de segurado e ao atingimento da carência que é o número mínimo de contribuições mensais vertidas para a Previdência Social. A qualidade de segurado é a condição atribuída a todo cidadão filiado ao Instituto Nacional do Seguro Social (INSS) que possua uma inscrição e faça pagamentos mensais a título de Previdência Social. Entretanto, a legislação determina que, mesmo em algumas condições sem recolhimento, esses filiados ainda manterão esta qualidade, o que é denominado "período de graça"14. Esta foi a situação de 51\% dos beneficiários deste estudo, os quais estavam recebendo benefícios previdenciários e acidentários, mesmo não estando contribuindo. Os demais, por não atenderem a critérios da previdência, recebiam benefícios assistenciais. As quatorze maiores taxas de incidências de benefícios a desempregados foram em UFs do norte e nordeste. A desigualdade territorial deste indicador reflete a diversidade econômica e sociocultural do Brasil, demonstrando a vulnerabilidade sociais a que estas populações estão submetidas.

Havendo a perda da qualidade de segurado, as contribuições anteriores a essa perda somente serão computadas para efeito de carência depois que o segurado contar, a partir da nova filiação 
ao RGPS, com no mínimo 50\% das contribuições para o benefício a ser pleiteado, conforme o Art. $1^{\circ}$ da Lei $n^{\circ} 13.457 / 2017^{15}$. No caso em estudo não há que se falar em carência como requisito para concessão dos benefícios previdenciários, pois a aids encontra-se listada nas doenças isentas de carência, de acordo com o Art. 151 da Lei de Benefícios Previdenciários ${ }^{16}$. Todavia, a qualidade de segurado era, e ainda é indispensável para o reconhecimento do direito a esses benefícios desde que o início da incapacidade para o labor, recaia dentro do lapso de tempo compreendido entre o seu retorno ao RGPS e a data do afastamento de sua atividade, se empregado (a), trabalhador (a) avulso (a) e empregado (a) doméstico (a). Para os demais requerentes do benefício previdenciário tanto a data do início da doença como a data do início da incapacidade devem recair após o retorno ao RGPS ${ }^{15,17}$. Caso o requerente não se enquadre nos critérios acima, há a possibilidade de pleitear o benefício assistencial ${ }^{18}$. Foi avaliado o tipo de despacho realizado pelo INSS na concessão de benefícios. Importante destacar que existem vários códigos de despachos previstos para a concessão e indeferimento dos benefícios em geral. Este estudo destacou os três tipos de despachos mais comuns, sendo a concessão normal, que é quando todos os critérios exigidos no momento da concessão são preenchidos, tais como doença incapacitante para o labor, qualidade de segurado, carência ou enquadramento nos critérios de benefício assistencial, por exemplo.

Destacamos também a concessão embasada no artigo 27 do Decreto 3048/99. Neste artigo é esclarecido em que havendo perda da qualidade de segurado, as contribuições anteriores a essa perda poderão são computadas para efeito de carência, somando com as contribuições da nova filiação ao RGPS. Atualmente, para as contribuições anteriores serem computadas, deve-se ter cumprido, na nova filiação, no mínimo $50 \%$, do número de contribuições exigidas para o cumprimento da carência para o benefício a ser pleiteado, conforme o Art. $1^{\circ}$ da Lei No $13.457 / 2017^{12}$. Como já discutido, a concessão de benefícios no caso de beneficiários que convivem com a aids independe de carência. Porém, mesmo assim, os beneficiários que convivem com a aids e que não contribuem por períodos contínuos na previdência social são enquadrados neste critério. Nesta casuística, 52,3\% dos benefícios concedidos foram por meio do artigo 27 do Decreto 3048/99, refletindo instabilidade nos empregos, desemprego e segregação no mercado de trabalho a que estes indivíduos estão submetidos.
O RGPS do Brasil adota o sistema financeiro de repartição simples. Pode-se dizer que esse regime propõe uma transferência direta entre gerações, pois os trabalhadores ativos (geração atual) pagam os benefícios dos inativos (geração passada), enquanto o pagamento dos seus próprios benefícios dependerá da geração futura (novos trabalhadores que ingressarem no sistema previdenciário) manter a transferência intergeracional. O tratamento adequado da aids, ofertado pelo MS, desde o diagnóstico do vírus, aumentou a longevidade e qualidade de vida dos indivíduos com HIV/ aids. Esse fato, aliado ao aumento do número de casos de aids nos últimos anos e a informalidade no mercado de trabalho, impacta significativamente o sistema financeiro e econômico do Brasi ${ }^{19,20}$. Deve-se destacar que somente em 2014, foi aprovada pela Turma Nacional de Uniformização dos Juizados Especiais Federais (TNU) a Súmula 78, que discute sobre a requisição de benefícios previdenciários pelos portadores de HIV. Ficou estabelecido que no caso dos portadores do HIV, mesmo os assintomáticos, a incapacidade transcende a mera limitação física, e repercute na esfera social do requerente, segregando-o do mercado de trabalho. Sendo assim, aspectos pessoais, econômicos, sociais e culturais devem também ser considerados na caracterização da incapacidade ${ }^{21}$. A síndrome por si só em geral não incapacita para o trabalho, porém o estigma social ainda impacta sobremaneira o acesso ao mercado de trabalho, o que pode ser comprovado pelo elevado número de desempregados e de benefícios assistenciais concedidos no nosso estudo.

As análises dos resultados revelaram ainda, que os benefícios previdenciários e assistenciais foram concedidos em sua grande maioria para os indivíduos residentes em zona urbana e de forma esperada, as maiores taxas de incidências de benefícios foram nas UFs do Rio de Janeiro e São Paulo. Parte pode ser explicada pelo fato de que a população urbana no Brasil, segundo dados do IBGE é de $84,4 \%{ }^{22}$. O menor número de casos na zona rural, apesar da escassa literatura sobre o assunto, reflete o número reduzido de benefícios concedidos. Fatores socioculturais como a pobreza, a baixa escolaridade, a deficiência dos serviços de saúde, trabalho informal, além do isolamento geográfico também distanciam a população rural de seus direitos sociais em relação a aids ${ }^{23,24}$. Além disso, na maioria das vezes a população rural consegue produzir meios próprios para sua subsistência e de sua família, sendo dispensável a busca de benefícios ao RGPS ${ }^{25}$. As UFs do Mara- 
nhão, Piauí, Acre e Rio Grande do Norte tiveram as mais altas taxas de incidência de benefícios na zona rural, todas acima de 100 casos a cada 1000 benefícios. Em média, as quatro UFs tiveram taxas de incidências quatro vezes maiores que as demais. Este fato pode ser atribuído a serviços de saúde e de direitos sociais mais eficientes na zona rural destes locais, porém as conclusões sobre este assunto carecem de estudos técnico-científicos in loco mais aprofundados.

Os avanços tecnológicos alcançados com a introdução da terapia antirretroviral delegaram à aids a condição de cronicidade. Entretanto, o sistema de seguridade social brasileiro sofre duras consequências para suportar o seu tripé (saúde, previdência e assistência social). Esse cenário é, sem dúvida, um desafio para o Brasil, uma vez que as desigualdades regionais são gritantes e apesar de todo o investimento e gastos com a seguridade social, a doença persiste em progressão com níveis cada vez mais elevados e na fase da vida mais produtiva.

\section{Colaboradores}

KAR Santos e JE Limongi trabalharam na concepção, planejamento, análise e interpretação dos dados, na revisão crítica do conteúdo e também na aprovação da versão final do manuscrito. AMM Oliveira, AMG Bós e L Melo trabalharam na concepção, análise e interpretação dos dados e na aprovação da versão final do manuscrito.
Neste estudo, havia dados de concessões de benefícios, valores pagos, bem como as durações de cada benefício, sendo permitido o cálculo dos gastos com os benefícios relacionados à aids. A comparação com os dados gerais da previdência e assistência social, no entanto, foi prejudicada pela indisponibilidade dos dados de duração dos benefícios no Anuário Estatístico da Previdência Social. Esta foi considerada a principal limitação do estudo. Porém, para os gastos médios mensais no ano de 2016, foi possível realizar a comparação de forma legítima. Os valores dos benefícios relacionados a aids foram inferiores quando comparados aos valores pagos de forma geral pela na previdência social.

Os cortes orçamentários que têm atingido drasticamente o Sistema Único de Saúde e a educação no Brasil, coloca em risco todos os avanços alcançados até aqui, sob a perspectiva de aumentar ainda mais o impacto da aids em todas as esferas da seguridade social.

\section{Referências}

1. Grangeiro A, Silva LL, Teixeira PR. Resposta à AIDS no Brasil: contribuições dos movimentos sociais e da reforma sanitária. Rev Panam Salud Publica 2009; 26(1):87-94.

2. Brasil. Ministério da Saúde. Boletim Epidemiológico AIDS e DST. Brasília. Secretaria de Vigilância em Saúde, PN de DST e AIDS, Ano V, n. 1, 1a à 26 semanas epidemiológicas, jan./jun. 2017.

3. Governo do Brasil. SUS oferece melhor tratamento do mundo para pacientes com HIV/AIDS [Internet]. [acessado 2017 Dez 28]. Disponível em: http:// www.brasil.gov.br/saude/2016/09/sus-oferece-melhor-tratamento-do-mundo-para-pacientes-com-hiv -aids/@@itf_custom_galleria

4. Brasil. Ministério da Saúde (MS). Protocolo clínico e diretrizes terapêuticas para manejo da infecção pelo HIV em adultos. Brasília: MS, 2013

5. Brasil. Ministério da Saúde (MS). Ampliação de uso dos medicamentos antirretrovirais dolutegravir (DTG) e darunavir (DRV), já disponibilizados pelo Ministério da Saúde para o tratamento da infecção pelo HIV. Relatório de recomendação [Internet]. [acessado $2017 \mathrm{Dez}$ 28]. Disponível em: http://conitec.gov.br/images/Relatorios/2016/Relatorio_DolutegravirDarunavir_final.pdf

6. Nakagawa F, May M, Phillips A. Life expectancy living with HIV: Recent estimates and future implications. Curr Opin Infect Dis 2013; 26(1):17-25. 
7. Programa Conjunto das Nações Unidas sobre HIV/ AIDS (UNAIDS). Ending AIDS: Progress towards the 90-90-90 targets [Internet]. [acessado 2017 Dez 28]. Disponível em: http://www.unaids.org/en/resources/ documents/2017/20170720_Global_AIDS_update_2017

8. Santos KAR, Melo L, Oliveira AMM, Limongi JE. Social welfare related to AIDS in Brazil: factors associated with social assistance and social security, 20042016. Rev Panam Salud Publica 2018; 42:e73.

9. Kerr L, Kendall C, Guimarães MDC, Mota RS, Veras MA, Dourado I, Brito AM, Merchan-Hamann E, Pontes AK, Leal AF, Knauth D, Castro ARCM, Macena RHM, Lima LNC, Oliveira LC, Cavalcantee MS, Benzaken AS, Pereira G, Pimenta C, Pascom ARP, Bermudez XPD, Moreira RC, Brígido LFM, Camillo AC, McFarland W, Johnston LG. HIV prevalence among men who have sex with men in Brazil: results of the 2nd national survey using respondent-driven sampling. Medicine 2018; 97(Supl. 1):S9-S15.

10. Brasil. Ministério do Trabalho e Emprego. Observatório Nacional do Mercado de Trabalho. Participação feminina no mercado de trabalho [Internet]. [acessado em 2017 Mar 08]. Disponível em: http://obtrabalho. mte.gov.br/images/artigos/Boletim-Especial-do-Observatrio-Mulher-e-Mercado-de-Trabalho.pdf

11. Organização Internacional do Trabalho. Mulheres no trabalho: tendências, 2016 [Internet]. Brasília, Genebra: OIT; 2016. [acessado 2017 Dez 30]. Disponível em: http://www.ilo.org/wcmsp5/groups/public/--dgreports/---dcomm/---publ/documents/publication/wcms_457096.pdf

12. Lourenço EAS, Lacaz FAC, Goulart PM. Crise do capital e o desmonte da Previdência Social no Brasil. Serv Soc Soc 2017;130:467-486.

13. Brasil. Constituição da República Federativa do Brasil de 1988. Diário Oficial da União 1988; 5 out.

14. Brasil. Decreto no 3.048 , de 06 de maio de 1999. Aprova o regulamento da Previdência Social e dá outras providências (1988). Diário Oficial da União; 1999.

15. Brasil. Lei $\mathrm{n}^{\circ} 13.457$, de 26 de junho de 2017. Altera as Leis n. 8.213, de 24 de julho de 1991, que dispõe sobre os Planos de Benefícios da Previdência Social, e 11.907, de 2 de fevereiro de 2009, que dispõe sobre a reestruturação da composição remuneratória da Carreira de Perito Médico Previdenciário e da Carreira de Supervisor Médico-Pericial; e institui o Bônus Especial de Desempenho Institucional por Perícia Médica em Benefícios por Incapacidade. Diário Oficial da União; 2017.

16. Brasil. Lei no 8.123 , de 24 de julho de 1991. Dispõe sobre os planos de benefícios da previdência social e dá outras providências. Diário Oficial da União; 1991.

17. Brasil. Manual de Perícia da Previdência Social [Internet]. [acessado 2017 Dez 30]. Disponível em: http:// www.cpsol.com.br/upload/arquivo_download/1872/ Manual\%20Pericia\%20Medica\%20da\%20Previdencia\%20Social.pdf
18. Brasil. Lei no 8.742, de 07 de dezembro de 1993. Dispõe sobre a organização da Assistência Social e dá outras providências. Diário Oficial da União; 1993.

19. Matos PRF, Melo FSP, Simonassi AG. Análise de solvência do regime geral da previdência social no Brasil. Estud Econ São Paulo 2013; 43:301-333.

20. Butsch NM. O Regime Geral da Previdência Social: regime de repartição simples ou de capitalização [Internet]. Âmbito Jurídico 2017. [acessado 2017 Dez 30]. Disponível em: http://ambito-juridico.com.br/ site/index.php?n_link=revista_artigos_leitura\&artigo_id $=193558$ revista_caderno $=20$

21. Brasil. Turma Nacional de Uniformização dos Juizados Especiais Federais. SUM-78. Comprovado que o requerente de benefício é portador do vírus HIV, cabe ao julgador verificar as condições pessoais, sociais, econômicas e culturais, de forma a analisar a incapacidade em sentido amplo, em face da elevada estigmatização social da doença [Internet]. Brasília; 2014 [acessado 2018 Fev 28]. Disponível em: www.cjf.jus.br/cjf/ noticias/2014/setembro/tnu-aprova-sumula-78

22. Instituto Brasileiro de Geografia e Estatística (IBGE). Pesquisa Nacional por Amostra de Domicílios, 2015Porcentagem de residentes na zona urbana e rural. Rio de Janeiro: IBGE; 2017.

23. Parker R, Camargo Jr KR. Pobreza e HIV/AIDS: aspectos antropológicos e sociológicos. Cad Saude $\mathrm{Pu}$ blica 2000; 16(Supl. 1):89-102.

24. Furtado FMSF, Santos JAG, Loredanna S, Araújo E, Saldanha AAW, Silva J. 30 years later: Social Representations about AIDS and sexual practices of rural towns residents. Rev Esc Enferm USP 2016; 50(esp):74-80.

25. Baiardi A, Alencar CMM. Agricultura familiar, seu interesse acadêmico, sua lógica constitutiva e sua resiliência no Brasil. Rev Econ Sociol Rural 2014; 52(Supl. $1): 45-62$.

Artigo apresentado em 06/02/2018

Aprovado em 11/09/2018

Versão final apresentada em 13/09/2018 